\title{
市街地の建物における空調による人工排熱負荷の数值解析
}

\section{Numerical Analysis of the Building Air Conditioning Induced Antropogenic Heat in Urban Areas}

\author{
○ヴタンカ*, 足永 靖信**, 浅枝 隆***, 藤野 毅**** \\ Vu Thanh $\mathrm{Ca}^{*}$, Yasunobu Ashie ${ }^{* *}$, Takashi Asaeda ${ }^{* * *}$ and Takeshi Fujino***
}

ABSTRACT: A model for the evaluation of building air conditioning energy and exausted heat from air conditioning system during sumer is developed. The purpose of the model is to study a dynamic interaction between buildings in the urban areas and outside air. Three-dimensional ensemble-space averaged Reynolds equations, continuity equation, equations for the transport of turbulent energy, turbulent energy dissipation rate and heat and moisture transfer equations in the atmosphere were numerically integrated. Forest and building canopies were also incorporated in the model by the computation of momentum, heat and moisture exchange between the canopy and the air. Especially, a volume averaging technique, which allows an accounting for the volume of urban structures in the governing equations was applied.

For the computation of the building cooling energy, the conduction heat to the building is evaluated by computing the heat exchange between building walls and roof with air in the rooms using an assumption of constant room air temperature. The total heat load in the room is evaluated by the summation of this conduction heat and other heat sources in the room, such as heat release due to machines and anthropogenic heat. The needed air conditioning electricity is evaluated by this total heat load and a coefficient of performance (COP) of the heat pump, defined as the ratio between the heat load, needed to be pumped out of the room and the used electricity. The outside anthropogenic heat release due to air conditioning was evaluated as a summation of used electricity and the in-the-room heat load.

The model was also used for an analysis of the heating processes and cooling energy use for a model city.

KEYWORDS: Anthpogenic Heat, Turbulent Closure Model, Air Conditioning Electricity, Urban Thermal Environment, Urban Canopy

1. 初めに

都市の熱環境が周辺の自然の熱環境に比較して特異なものになっていることはよく知られてい る。都市の気候を改善するためには、都市域における人工排熱の制御と地表面被覆の改善が必要 である。しかしながら、建築躯体と空調設備特性が内外の気候に忘じて外界に放熱を行っている が、室内の空調負荷の時間変動や外部環境へ放出される熱の算定方法、さらに外部熱環境に及ぼ している問題の解決を残している。

このような観点から本研究では街区スケールの熱環境予測に適用するためのモデルを開発し、 都市キャノピー内外の一般的な熱環境特性を再現することを試みた。さらに、室内空調機器の外 部放熱を空調負荷と外部気温により関数化し、各建物からの空調負荷をそれぞれ算出することに より市街地の熱負荷を求め、建物と屋外熱環境のダイナミックな相互作用を算出することを試みた。

*埼玉大学助教授 Assoc. Prof., Saitama Univ.

**建設省建築研究所工学博士 Dr.E. Bld. Res. Inst.
***埼玉大学助教授 Assoc. Prof., Saitama Univ. **** 埼玉大学助手 PhD, Res. Assoc., Saitama Univ. 


\section{2. 街区スケールの気候モデルの概要}

\section{1 メゾスケールモデルの基本方程式}

Crapsiteら (1986)、平岡 (1991) による ensembleおよび空間平均法を用い、都市域における気

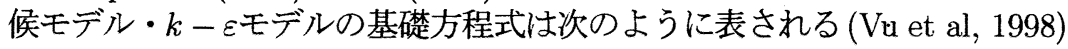

連続方程式

$$
\frac{1}{G} \frac{\partial G U}{\partial x}+\frac{1}{G} \frac{\partial G V}{\partial y}+\frac{1}{G} \frac{\partial G W^{*}}{\partial z^{*}}-\frac{1}{H-z_{\dot{g}}}\left(U \frac{\partial z_{g}}{\partial x}+V \frac{\partial z_{g}}{\partial y}\right)=0
$$

運動方程式

$$
\begin{array}{r}
\frac{\partial U}{\partial t}+\frac{1}{G} \frac{\partial G U U}{\partial x}+\frac{1}{G} \frac{\partial G U V}{\partial y}+\frac{1}{G} \frac{\partial G U W^{*}}{\partial z^{*}}=-\frac{\partial P}{\partial x}+\frac{1}{G} \frac{\partial}{\partial x}\left(\nu_{t} \frac{\partial G U}{\partial x}\right) \\
+\frac{1}{G} \frac{\partial}{\partial y}\left(\nu_{t} \frac{\partial G U}{\partial y}\right)+\left(\frac{\bar{H}}{H-z_{g}}\right)^{2} \frac{1}{G} \frac{\partial}{\partial z^{*}}\left(\nu_{t} \frac{\partial G U}{\partial z^{*}}\right)-a c_{f} U\left(U^{2}\right)^{1 / 2} \\
\frac{\partial V}{\partial t}+\frac{1}{G} \frac{\partial G V U}{\partial x}+\frac{1}{G} \frac{\partial G V V}{\partial y}+\frac{1}{G} \frac{\partial G V W^{*}}{\partial z *}=-\frac{\partial P}{\partial y}+\frac{1}{G} \frac{\partial}{\partial x}\left(\nu_{t} \frac{\partial G V}{\partial x}\right) \\
+\frac{1}{G} \frac{\partial}{\partial y}\left(\nu_{t} \frac{\partial G V}{\partial y}\right)+\left(\frac{\bar{H}}{H-z_{g}}\right)^{2} \frac{1}{G} \frac{\partial}{\partial z^{*}}\left(\nu_{t} \frac{\partial G V}{\partial z^{*}}\right)-a c_{f} V\left(U^{2}\right)^{1 / 2} \\
0=-\frac{\bar{H}}{H-z_{g}} \frac{\partial P}{\partial z}-\varrho g
\end{array}
$$

乱れのエネルギー $k$ の式

$$
\begin{gathered}
\frac{\partial k}{\partial t}+\frac{1}{G} \frac{\partial G U k}{\partial x}+\frac{1}{G} \frac{\partial G V k}{\partial y}+\frac{1}{G} \frac{\partial G W^{*} k}{\partial z^{*}}=P_{k}+F_{k}-\varepsilon+\frac{1}{G} \frac{\partial}{\partial x}\left[\nu_{t} \frac{C_{r r}}{\sigma_{t}} \frac{\partial G k}{\partial x}\right] \\
+\frac{1}{G} \frac{\partial}{\partial y}\left[\nu_{t} \frac{C_{r r}}{\sigma_{t}} \frac{\partial G k}{\partial y}\right]+\left(\frac{\bar{H}}{H-z_{g}}\right)^{2} \frac{1}{G} \frac{\partial}{\partial z^{*}}\left[\nu_{t} \frac{C_{r r}}{\sigma_{t}} \frac{\partial G k}{\partial z^{*}}\right]-\frac{\bar{H}}{H-z_{g}} g \beta K_{T} \frac{\partial \Theta}{\partial z^{*}}
\end{gathered}
$$

粘性消散 $\varepsilon$ 式

$$
\begin{array}{r}
\frac{\partial \varepsilon}{\partial t}+\frac{1}{G} \frac{\partial G U \varepsilon}{\partial x}+\frac{1}{G} \frac{\partial G V \varepsilon}{\partial y}+\frac{1}{G} \frac{\partial G W^{*} \varepsilon}{\partial z^{*}}=\frac{\varepsilon}{k}\left[C_{1 \varepsilon} P_{k}+C_{\rho \varepsilon} F_{\varepsilon}-C_{2 \varepsilon} \varepsilon\right]+\frac{1}{G} \frac{\partial}{\partial x}\left[\frac{\nu_{t}}{\sigma_{\varepsilon}} \frac{\partial G \varepsilon}{\partial x}\right] \\
+\frac{1}{G} \frac{\partial}{\partial y}\left[\frac{\nu_{t}}{\sigma_{\varepsilon}} \frac{\partial G \varepsilon}{\partial y}\right]+\left(\frac{\bar{H}}{H-z_{g}}\right)^{2} \frac{1}{G} \frac{\partial}{\partial z^{*}}\left[\frac{\nu_{t} G}{\sigma_{\varepsilon}} \frac{\partial G \varepsilon}{\partial z^{*}}\right]+c_{3 \varepsilon} \frac{\bar{H}}{H-z_{g}} \frac{\varepsilon}{k} g \beta K_{T} \frac{\partial \Theta}{\partial z^{*}}
\end{array}
$$

熱拡散方程式

$$
\begin{aligned}
\frac{\partial \Theta}{\partial t}+ & \frac{1}{G} \frac{\partial G U \Theta}{\partial x}+\frac{1}{G} \frac{\partial G V \Theta}{\partial y}+\frac{1}{G} \frac{\partial G W^{*} \Theta}{\partial z^{*}}+R_{r e \theta}=\frac{1}{G} \frac{\partial}{\partial x}\left(K_{T} G \frac{\partial \Theta}{\partial x}\right) \\
+ & \frac{1}{G} \frac{\partial}{\partial y}\left(K_{T} G \frac{\partial \Theta}{\partial y}\right)+\left(\frac{\bar{H}}{H-z_{g}}\right)^{2} \frac{1}{G} \frac{\partial}{\partial z^{*}}\left(K_{T} G \frac{\partial \Theta}{\partial z^{*}}\right)+\frac{H_{s}}{\rho_{a} C_{p} G}
\end{aligned}
$$

水蒸気拡散方程式

$$
\begin{array}{r}
\frac{\partial Q}{\partial t}+\frac{1}{G} \frac{\partial G U Q}{\partial x}+\frac{1}{G} \frac{\partial G V Q}{\partial y}+\frac{1}{G} \frac{\partial G W^{*} Q}{\partial z^{*}}+R_{r e Q}=\frac{1}{G} \frac{\partial}{\partial x}\left(K_{T} G \frac{\partial Q}{\partial x}\right) \\
+\frac{1}{G} \frac{\partial}{\partial y}\left(K_{T} G \frac{\partial Q}{\partial y}\right)+\left(\frac{\bar{H}}{H-z_{g}}\right)^{2} \frac{1}{G} \frac{\partial}{\partial z^{*}}\left(K_{T} G \frac{\partial Q}{\partial z^{*}}\right)+\frac{Q_{s}}{\rho_{a} G}
\end{array}
$$


ここで $U, V, W, \Theta, Q$ はそれぞれ平均化された風速成分、仮温位および氷蒸気混合比、Pは圧力、 $\nu_{t}$ は渦粘性係数、 $K_{T}$ は渦拡散係数、 $\beta$ は空気の体積膨張率、 $\rho_{a}$ は空気の密度、 $g$ は重力の加速度で ある。 $C_{r r} 、 C_{1 \varepsilon} 、 C_{2 \varepsilon} 、 C_{3 \varepsilon} 、 C_{\rho \varepsilon} 、 \sigma_{t}$ はそれぞれクロジャ一定数を示す。 $H_{s}$ は熱負荷、 $Q_{s}$ は水蒸気 源を示す。ここで、式(2)-(4) 中の圧力の扱いけ静水圧の仮定を用いた。

また、ビルキャノピー内の空気の有効体積率 $G$ を次式で定義する

$$
G(x)=\frac{V_{a}(x)}{V_{0}}
$$

ここで $V_{0}$ は任意体積、 $V_{a}$ は $V_{0}$ 内の気体体積である。

乱流のエネルギーの生成項、レノルズ応力、粘性係数などは以下のように表される:

$$
\begin{array}{r}
P_{k}=-\overline{u v} \frac{\partial U}{\partial y}-\overline{u w} \frac{\partial U}{\partial z}-\overline{v u} \frac{\partial U}{\partial x}-\overline{v w} \frac{\partial U}{\partial z}-\overline{w u} \frac{\partial W}{\partial x}-\overline{w v} \frac{\partial W}{\partial y}, \\
\overline{u_{i} u_{j}}=-\frac{\nu_{t}}{G}\left(\frac{\partial G U_{i}}{\partial x_{j}}+\frac{\partial G U_{j}}{\partial x_{i}}\right), \\
\nu_{t}=C_{D} \frac{k^{2}}{\varepsilon}, \quad F_{k}=U_{i} a C_{f i} U_{i}\left[U_{j}^{2}\right]^{1 / 2}, \quad F_{\varepsilon}=\frac{k^{3 / 2}}{L} .
\end{array}
$$

(11) 式の $L$ は物体によって作り出される渦の特徵長さを表す。 $W$ は式(13)による評価される。係数 $C_{\rho \varepsilon}$ と補正係数 $C_{r r}$ は空気の有効体積率 $G$ や壁面積密度など、平均化体積内部の特性量に依存する。

ただし、次の座標変換を用いた

$$
z=z^{*} \frac{H-z_{g}}{\bar{H}}+z_{g}
$$

ここに $H$ は $z$ 座標系における計算領域の最大高さ、 $\bar{H}$ は $z^{*}$ 座標系における計算領域の最大高さ、 $z_{g}$ は $z$ 座標系における地面標高である。 $z^{*}$ 座標系における鉛直風速成分は次式で表される

$$
W^{*}=W \frac{\bar{H}}{H-z_{g}}+\frac{z^{*}-\bar{H}}{H-z_{g}}\left(\frac{\partial z_{g}}{\partial x} U+\frac{\partial z_{g}}{\partial y} V\right)
$$

2.2 ビルキャノピーモデル

都市熱環境を表現するためには、都市キャノピー層のモデル化が不可欠であり、、その効果を 次のように見積もる。ビル表面の見積もりはビル表面の熱収支式

$$
-\lambda_{c} \frac{\partial T_{c}}{\partial z_{c}}=R_{N c}+H_{c}
$$

と、ビル表面に対する垂直 1 次元熱伝導方程式

$$
\frac{\partial T_{c}}{\partial t}=\frac{\lambda_{c}}{\rho C_{c}} \frac{\partial^{2} T_{c}}{\partial z_{c}^{2}}
$$

を用いる。ここで、 $z_{c}$ は表面から垂直外向きを正とする。 $T_{c}$ はビル表面内の温度、 $R_{N c}$ は表面で受 ける正味放射、 $H_{c}$ は表面からの顕熱、 $\lambda_{c}$ は表面内の熱伝導率、 $\rho C_{c}$ は表面内の熱容量を示す。正味 放射の見積りはVu ら (1998) に従って、建物と道路の形態を評価し周囲にビルの表面及び道路表面 からの多種反射の効果を考慮した。 


\section{3. 建物の冷房モデル}

市街地における建物からの空調負荷を算定する方法としては、あるエリア内において、用途お よび規模が異なるいくつかの建物を設定し、各建物からの空調負荷をそれぞれ算出することによ り求める。

建物の冷房にはヒートポンブなどの泠房熱源機器を用い、電力やガスなどのエネルギーを熱源 機器に投入して室内の熱負荷を外部に放出するが、冷房で建物が放出する熱負荷は室内の冷房負 荷の他にも冷房熱源機器が使用するエネルギー(電力、ガスなど) も最終的に熱負荷として外部に 放出される。

室内の熱負荷は外壁面から室内へ伝導する熱量および室内の活動により生ずる熱照明・人体・ 機器発熱である。外壁面から室内一伝導する熱量はJurges式により示す。すなわち

$$
H_{r}=6.15\left(T_{w}-T_{r}\right)
$$

ここで $H_{r}$ は室内への熱伝導量、 $T_{w}$ は壁や屋根の内面温度、 $T_{r}$ は室内の気温である。夏季では室内 の気温は $26^{\circ} \mathrm{C}$ とする。

冷房熱源機器が使用するエネルギー量は各熱源機器の成績係数 (COP) をもとに算出できるが、 COP は定格および部分負荷運転で值が異なり、さらには外気条件によっても大きく変動する。建 物設備の熱負荷特性に応じたヒートポンプのCOPの值を従属変数として、気温条件と部分負荷率 による関数化を行なった。ビル用マルチヒートポンプの場合はCOPは次式に示される

$13 \mathrm{HP}$ ビル用マルチヒートポンプの場合

$$
\begin{array}{r}
\mathrm{COP}=\left(-0.000031675 T_{a}^{4}+0.003815004 T_{a}^{3}-0.169787502 T_{a}^{2}+3.257890284 T_{a}\right. \\
-20.4130268) \times\left(0.705669303 X^{4}+2.629505723 X^{3}+2.063122179 X^{2}\right. \\
-0.721753935 X+1.478213004)
\end{array}
$$

18HP ビル用マルチヒートポンプの場合

$$
\begin{array}{r}
\mathrm{COP}=\left(-0.000126461 T_{a}^{4}+0.015932305 T_{a}^{3}-0.7349959368 T_{a}^{2}+14.18266913 T_{a}\right. \\
-73.65971787) \times\left(0.043862886 X^{4}+0.175302306 X^{3}+0.110860776 X^{2}\right. \\
-0.106109183 X+0.15324716)
\end{array}
$$

20HP ビル用マルチヒートポンプの場合

$$
\begin{array}{r}
\mathrm{COP}=\left(-0.000276426 T_{a}^{4}+0.035140747 T_{a}^{3}-1.636123697 T_{a}^{2}+32.001289 T_{a}\right. \\
-175.8289164) \times\left(0.013976463 X^{4}+0.052752243 X^{3}+0.010714986 X^{2}\right. \\
-0.072098548 X+0.073785827)
\end{array}
$$

ここで $T_{a}$ は外気温度 (乾球温度)、 $X=\ln (Y) 、 Y$ はヒートボンプの部分負荷率であり、次式で定義 される

部分負荷率 $Y=\left(\right.$ 建物の空調熱負荷 $\left.H_{L}\right) /($ 空調機の台数 $n) /\left(\right.$ 空調機の可能最大負荷 $\left.H_{L m a x}\right) 。$

空調機の可能最大負荷 $H_{L \max }$ は定格出力とも呼ばれるもので空調機の機種により異なり、機種 で一義的に定まる定数である。空調消費電力量を次式に示す

空調消費電力量 $\left(D_{e}\right)=$ 建物の空調熱負荷 $H_{L} / \mathrm{COP}$

最後に、市街地における建物の空調排熱量を $H_{\text {antr }}$ とすると

$$
H_{\text {antr }}=D_{\epsilon}+H_{L}
$$




\section{4. 計算条件}

計算で用いた土地利用条件はコンクリート舗装(熱伝導係数: $1.69 \mathrm{Wm}^{-1} \mathrm{~K}^{-1}$, 比熱: $2.07 \mathrm{Jcm}^{-3}$ $\mathrm{K}^{-1}$, 反射率: 0.2 ) 面上に 5 階建て高さ $20 \mathrm{~m}$ 、幅 $20 \mathrm{~m}$ のオフィスビルが立っているものとした。 $16 \mathrm{~km}$ $\times 16 \mathrm{~km}$ の正方形の計算領域を $40 \times 40$ メッシュに、5000m 高さの計算領域を 22 メッシュに分けた。 地面近傍の鉛直方向の最小のメッシュを $2 \mathrm{~m}$ とし、上に向かってメッシュ高さが増加させる。計算 領域上端では、それぞれ風速、内部エネルギー、水蒸気の混合比の乱流フラックスは生じないも のと仮定し、初期值で与えた值がそのまま維持されるものとした。計算領域上端の風速を一定の $5 \mathrm{~m} / \mathrm{s}$ とした。計算領域の側面での值は側面の垂直方向の勾配をゼロとした計算を行った。従って、 計算領域の側面の境界值は時間と共に変化する。交通による人工排熱をゼロと仮定した。建物の 壁と屋根の構造及び熱特性はVu ら (1998) を参考した。建物の空調設備はビル用マルチ $18 \mathrm{HP} と し$ た。計算は 8 月の晴天日を対象にし、朝 5 時から 48 時間計算を行った。計算手順についてはまず、 メゾスケール・モデル，ビルキャノピー・モデルを用い屋内の熱負荷を求めた上に空調機の COP を計算した。次に空調消費電力量と建物の空調排熱量を求めた。このようにメゾスケール・モデ ル,ビルキャノピー・モデル、建物冷房・モデルを用い収束の計算を行った。

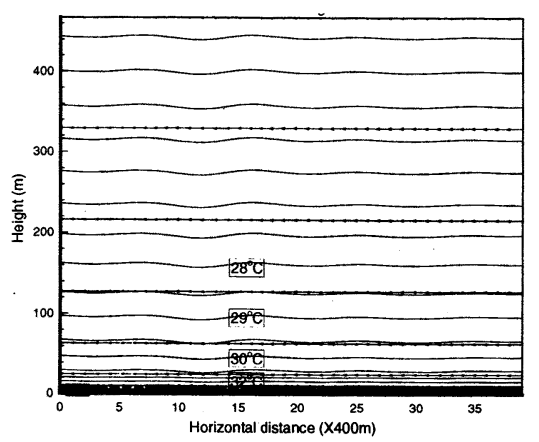

図 1 計算領域の断面の気温と風速 分布(建物なし)

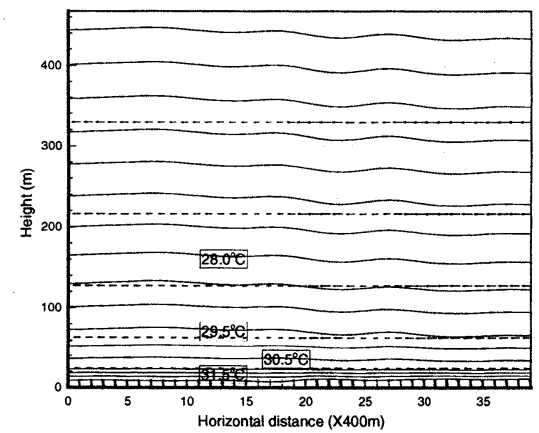

図 2 計算領域の断面の気温と風速 分布 (建蔽率 0.3 )

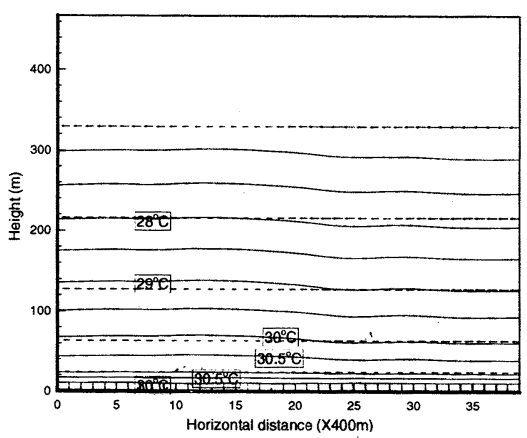

図3:計算領域の断面の気温と風速分布 (建蔽率0.3)

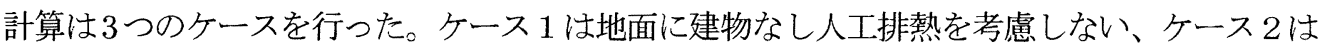
地面に建蔽率 0.3 の建物が覆われる場合; ケース 3 では建物の建蔽率を 0.7 とた。各建物の延べ床 面積を $2000 \mathrm{~m}^{2}$ とし、室内の照明、人体及び機器発熱による生ずる人工排熱の設定はVuら (1998) に従いそれぞれ $25 \mathrm{~W}, 12 \mathrm{~W}, 20 \mathrm{~W} /\left(\mathrm{m}^{2}\right.$ floor $)$ とした。 


\section{5. 計算結果}

図1-3には計算領域の断面における計算した午前 12 時の気温と風速分布を示す。まずケース 1 は地面付近の風速の鉛直分布をほぼ対数法則で表される。高さ $300 \mathrm{~m}$ の風速は $5 \mathrm{~m} / \mathrm{s}$ である。地面

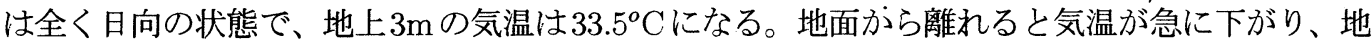
上 $20 \mathrm{~m}$ の気温は $31^{\circ} \mathrm{C}$ となる。次にケース 2 の建蔽率が 0.3 の場合は風速は高さ $20 \mathrm{~m}$ 以下では非常 に小さくなる。これは建物による生ずる抵抗力の影響を受けるためである。高さ $300 \mathrm{~m}$ の風速はほ ぼ $3.5 \mathrm{~m} / \mathrm{s}$ となる。高さ $10 \mathrm{~m}$ 以下の気温はほぼ一様に、 $33^{\circ} \mathrm{C}$ となる。このケースにおける地面付近 の気温は、ケース 1 より低く、これは地面には日陰があるためである。しかし地上 $20 \mathrm{~m}$ の高さの 気温は $31.5^{\circ} \mathrm{C}$ となっている。これは屋根からの顕熱および空調設備の放熱があるため、高さ $20 \mathrm{~m}$ の気温はケース 1 より高いことがわかる。ケース 3 は建蔽率が大きいため、地面付近の風速は殆ど ゼロであり、高さ $300 \mathrm{~m}$ の風速はほぼ $3.2 \mathrm{~m} / \mathrm{s}$ となる。地面の日陰の部分が大きいため、地面温度 は低く、地面付近の気温は $29.5^{\circ}$ となる。地面から離れると、気温が高くなる。高さ $20 \mathrm{~m} に 31^{\circ}$ の 最高気温を示す。

計算結果による建蔽率が大きくなるほど地上付近の気温が低下する。このことは、建物による 日射遮蔽効果が卓越していることを意味していると思われる。実際の都市街区は高密になるほど 高温になると思われることから、交通排熱を無視した点、建物の空調排熱位置等の仮定が適切で あったかどうかの検討および計算手法の改善が今後課題と思われる。

図4、5にケース2、ケース 3 における建物冷房モデルによって求められた空調設備の使用エネ ルギー、屋外に放出する熱負荷、空調設備の COP と屋外気温の時間変化を示す。図より暑い時刻 ではCOP は低下し、屋外に放出する熱負荷が上がることが明らかになった。今後、外気側の設定 がさらに現実的にすれば、高密のケースのCOP低下も顕著になるものと推測する。

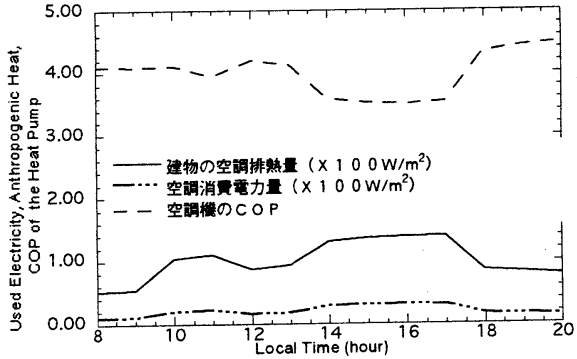

図4 空調消費電力量、空調排熱量 及びCOP の時間変化(建蔽率 0.3 )

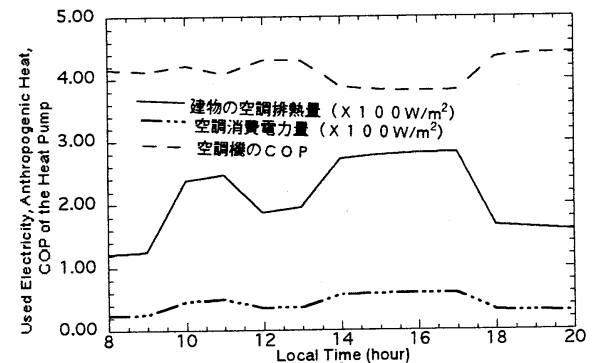

図 5 空調消費電力量、空調排熱量 及びCOP の時間変化 (建蔽率 0.7 )

6. まとめ

従来からの大気モデルの手法にビルキャノピーや建物からの熱環境負荷の影響を組み込んだ都 市域の風、気温、湿度、建物の空調設備の使用エネルギーのシミュレーションモデルを作成した。 将来は数值モデルの検討を行い、開発地区周辺の熱環境負荷を予測する予定である。

\section{参考文献}

G.H. Crapsite, E. Rotstein, and S. Whitaker (1986) A general closure scheme for the method of volume averaging. Chemical Engineering Science 41 (2), 227-235.

田中ら (1997) 保水性建材を用いた市街地熱環境計画手法の開発 その 4 空調設備の熱環境負荷 空気緩和・ 衛生工学会学術講演会講演論文集、1249-1252.

平岡 久司 (1989) 植物群落内および都市キャノピー内の乱流モデルに関する研究 (その1) 乱流モデルの作 成、日本建築学会計画系論文報告集第 406 号、1-9.

Vu Thanh Ca, Y. Ashie, T. Asaeda and T. Fujino (1998) A numerical Model for the Urban Climate. In preparation 